\title{
Differences in the Quality Characteristics between Commercial Korean Native Chickens and Broilers
}

\author{
Jun Ho Choe, Kichang Nam, Samooel Jung, Binna Kim, Hyejeong Yun, and Cheorun Jo* \\ Department of Animal Science and Biotechnology, Chungnam National University, Daejeon 305-764, Korea \\ Department of Animal Science, Sunchon National University, Sunchon 540-742, Korea
}

\begin{abstract}
To investigate the differences in the quality characteristics between commercial Korean native chicken (KNC) and broiler (CB), nutritive and quality parameters of the two chicken species were determined. The KNC thigh muscle had a lower content of crude fat and higher crude ash than the CB thigh. In regards to the fatty acid composition, KNC breast muscle had a higher content of arachidonic acid (C20:4) than CB. The level of inosine was higher in the CB thigh muscle than KNC but there was little difference in other nucleotide compounds. The KNC breast had higher amounts of glycine, alanine, and proline than $\mathrm{CB}$, which are closely related to high quality meat flavor. The sensory acceptance was not significantly different between the breast and thigh of KNC and CB. However, KNC had higher cohesiveness, chewiness and gumminess than CB, which are indicative of a unique texture property. Based on these results, commercial KNC may have superior nutritional quality, taste, and unique texture when compared with $\mathrm{CB}$. Thus, the consumer preference for KNC may be partially explained by these distinctive quality characteristics.
\end{abstract}

Key words: Commercial, Korean native chicken, broiler, quality, sensory

\section{Introduction}

With recent increases in household income, meat consumption is increasing rapidly and consumers' preferences for meats are changing to higher-quality products. Thus, there exists a growing interest in improving the meat quality of chickens. As poultry meat is a low-fat, low-cholesterol, low-calorie, and high-protein food, consumers have begun to prefer chicken to red meat, resulting in a dramatic increase in the quantity of available chicken meat, due to the development of new processed products (Ahn et al., 1997). According to the report of the Korean Ministry of Agriculture and Forestry, per capita consumption of poultry meats has increased by approximately $3 \mathrm{~kg}$ over the past few decades, from $5.6 \mathrm{~kg}$ in 1998 to $8.6 \mathrm{~kg}$ in 2007 (Chae et al., 2002).

Despite these recent increases in the preference for and consumption of chicken meat, traditional Korean native chickens (Gallus gallus domesticus) have not been produced in sufficient numbers, because large amounts of

*Corresponding author : Cheorun Jo, Department of Animal Science and Biotechnology, Chungnam National University, Daejeon 305-764, Korea. Tel: 82-42-821-5774, Fax: 82-42825-9754, E-mail: cheorun@cnu.ac.kr much cheaper foreign broilers have been imported under the FTA system.

Broilers, which can be sent out to market within 5-6 weeks, are the most predominantly available chicken species, owing to their excellent growth rate and lean muscle production ability. Thus, it tends to be more beneficial for a farm household to produce broilers than Korean native chickens, especially on a large scale (Ahn and Park, 2002). Korean native chickens evidence lower growth rates, feed efficiency, and lean muscle gaining ability than broilers, and also present difficulties in terms of the process of feather removal during the meat production process. Nevertheless, Korean native chickens are generally well-known for their excellent flavor and unique texture. Ahn and Park (2002) previously reported that large quantities of desirable amino acids and nucleic acids were detected in Korean native chickens, in particular, the inosine-5'-monophosphate (IMP) contents were higher in Korean native chickens than in foreign broilers.

Owing to the superior flavor and texture of Korean native chickens, consumers have become increasingly interested in Korean native chickens, and thus the market price of these chickens is routinely 1.5-2 times that of broilers (Ding et al., 1999). Occasionally, foreign broilers can be found being sold in markets at prices commensu- 
rate with those of Korean native chickens (Kim et al., 1999). Wattanachant et al. (2004) previously determined the differences between the Thai native chicken (Gallus domesticus) and broiler (Ross) via physicochemical analyses, demonstrating the superiority of the native Thai chicken. Saegusa et al. (1987) assessed the differences between native Japanese chicken and broilers. However, there is currently a paucity of scientific information available to explain the characteristic flavor and texture of native Korean chickens.

Generally, the compounds involved in meat flavor include free amino acids, nucleic acids, minerals, peptides, and volatiles. IMP is known as the major nucleotide in muscle that imparts flavor to the meat (Yamaguchi, 1991). The unique taste and texture of native Korean chickens have yet to be clearly evaluated via scientific analyses, and there is a clear need to elucidate the physicochemical factors influencing the taste and texture of these chickens. Therefore, the principal objective of this study was to determine the characteristic factors that affect the savory taste and texture of native Korean chickens as compared with general broilers, in terms of proximate composition, fatty acids, nucleic acids, amino acids, texture, and sensory characteristics.

\section{Materials and Methods}

\section{Sample preparation}

Ten commercial Korean native chickens (KNC) approximately $70 \mathrm{~d}$ of age (Gallus Gallus domesticus) and 10 commercial broilers (CB) aged approximately $32 \mathrm{~d}$ (Ross), were purchased from a local market (N mart, Daejeon, Korea). Breast and thigh muscles were deboned from the $\mathrm{KNC}$ and $\mathrm{CB}$, and the visible skin, fat, and connective tissues were removed. The KNC and CB breast (m. pectoralis) and thigh ( $m$. biceps fermoris) muscles were homogenized for analyses of proximate composition, $\mathrm{pH}$, water-holding capacity, color values, fatty acids, amino acids, texture, and sensory characteristics.

\section{Proximate composition}

The proximate composition of the breast and thigh muscles from each $\mathrm{KNC}$ and $\mathrm{CB}$ was determined via the AOAC technique (1995). In brief, moisture contents were measured by drying the samples $(2 \mathrm{~g})$ for $15 \mathrm{~h}$ at $102^{\circ} \mathrm{C}$. Crude protein content was measured via the Kjeldahl method (VAPO45, Gerhardt Ltd., Idar-Oberstein, Germany). The amount of nitrogen obtained was multiplied by 6.25 in order to calculate the crude protein contents.
Crude fat contents were measured via the Soxhlet extraction system (TT 12/A, Gerhardt Ltd., Idar-Oberstein, Germany). Crude ash content was measured by heating the sample ( $2 \mathrm{~g}$ ) overnight in a furnace, at a temperature of $600^{\circ} \mathrm{C}$.

\section{pH, water holding capacity, and color values}

In order to determine the $\mathrm{pH}$ values of each of the breast and thigh muscles, $10 \mathrm{~g}$ of each sample was mixed with $90 \mathrm{~mL}$ of distilled water and homogenized with a homomixer (T25 basic, Ika Co., Staufen, Germany) for 1 $\min$ at $1,130 \mathrm{~g}$. The mean value from 3 repeated measurements was determined with a $\mathrm{pH}$ meter (750P, Istek Co., Seoul, Korea).

Water holding capacity (WHC) was determined via a modified version of the method developed by Ryoichi et al. (1993). The minced meat sample (10 g) was placed into a centrifugation tube with a filter paper (No. 4, Whatman International Ltd., Maidstone England), then centrifuged for $10 \mathrm{~min}$ at $6,710 \mathrm{~g}$. The absorbed moisture in the filter paper was weighed and the moisture content of the meat sample $(10 \mathrm{~g})$ prior to centrifugation was determined after $15 \mathrm{~h}$ of drying at $102^{\circ} \mathrm{C}$. The WHC of the meat samples was calculated as the percentage of the absorbed moisture in the filter paper on the basis of the moisture content of the original meat sample.

Color values were measured on the surface of the meat samples (4 cm diameter, $1.5 \mathrm{~cm}$ thickness) with a colorimeter (Spectrophotometer, CM-3500d, Minolta, Tokyo, Japan). The colorimeter was calibrated against a black and a white reference tile, and a medium-sized aperture (4 cm diameter) was used. The color CIE L* (lightness), CIE $a^{*}$ (redness), and CIE b* (yellowness) values were obtained using an average value from 6 random readings on each sample surface for statistical analysis. Each color value was analyzed automatically using Spectra Magic Software (Minolta, Tokyo, Japan).

\section{Fatty acid composition}

Lipids were extracted from samples in accordance with the method of Folch et al. (1957), by mixing the meat samples $(30 \mathrm{~g})$ with $150 \mathrm{~mL}$ of Folch solution (chloroform: methanol $=2: 1$ ). To this solution, $0.88 \% \mathrm{KOH}$ was added, mixed vigorously while capped, and maintained for $2 \mathrm{~h}$ at room temperature. The upper layer was then removed and chloroform was evaporated using $\mathrm{N}_{2}$ gas (99.999\%). After cooling, $1 \mathrm{~mL}$ of methylating reagent $\left(\mathrm{BF}_{3}\right.$-methanol, Sigma Chemical Co., St. Louis, MO, USA) was added to $100 \mu \mathrm{L}$ of lipid, and heated for 30 
min at $70^{\circ} \mathrm{C}$. The samples were removed from the water bath and allowed to cool, and then $2 \mathrm{~mL}$ of hexane (HPLC grade) and $5 \mathrm{~mL}$ of distilled water were added to the samples. The samples were then vortexed and the upper layer was removed. The fatty acid methyl ester dissolved in hexane was transferred to a GC vial. The fatty acid composition was analyzed with a GC (Shimadzu Gas Chromatography 17-A, Tokyo, Japan), and a capillary column $(30 \mathrm{~m} \times 0.32 \mathrm{~mm} \times 0.25 \mu \mathrm{m}$ film thickness, Omegawax 320, Supelco Inc., Bellefonte, PA, USA). The oven was set to a temperature of $200^{\circ} \mathrm{C}$. The inlet and detector temperatures were $250^{\circ} \mathrm{C}$ and $260^{\circ} \mathrm{C}$, respectively. Helium was the carrier gas at a linear flow of 0.79 $\mathrm{mL} / \mathrm{min}$, and the split ratio was 100:1. Fatty acids were identified via comparison of retention times to known standards. Relative quantities were expressed as the weight percent of total fatty acids.

\section{Nucleotides}

The meat samples $(5 \mathrm{~g})$ were mixed with $25 \mathrm{~mL}$ of 0.7 $\mathrm{M}$ perchloric acid and centrifuged for $1 \mathrm{~min}$ at 1,130 $\mathrm{g}$ to extract nucleic acids. The extracted nucleic acids were then centrifuged for $15 \mathrm{~min}$ at 2,090 $\mathrm{g}$ and filtered through a Whatman No.4 filter paper (Whatman Inc., Clifton, NJ, USA). The supernatant was then adjusted to $\mathrm{pH} 7$ with 5 $\mathrm{N} \mathrm{KOH}$. The $\mathrm{pH}$-adjusted supernatant was placed in a volumetric flask and made up to a volume of $100 \mathrm{~mL}$ with $0.7 \mathrm{M}$ perchloric acid ( $\mathrm{pH} 7)$. After $30 \mathrm{~min}$ of cooling, it was centrifuged at $1,130 \mathrm{~g}\left(0^{\circ} \mathrm{C}\right)$ and the supernatant was filtered through a $0.2 \mu \mathrm{m}$ PVDF syringe filter (Whatman, Maidstone, England). The filtrate $(5 \mathrm{~mL})$ was analyzed using HPLC (ACME 9000, Younglin Instruments Inc., Seoul, Korea). With regard to the analytical conditions for HPLC, a Waters-Atlantis dC18 RP column (4.6×250 mm, $5 \mu \mathrm{m}$ particles, Waters Co., Milford, USA) was utilized, with a mobile phase of $0.1 \mathrm{M}$ triethylamine in $0.15 \mathrm{M}$ acetonitrile $(\mathrm{pH} 7.0)$. The flow rate of the mobile phase was $1.0 \mathrm{~mL} / \mathrm{min}$ and the injection volume was $10 \mu \mathrm{L}$. The column temperature was maintained at $35^{\circ} \mathrm{C}$ and the detection was monitored at a wavelength of $260 \mathrm{~nm}$. The peaks of the individual nucleotides were identified using the retention times for standards: hypoxanthine, inosine, inosine-5'-phosphate (IMP), adenosine-5'-phosphate (AMP) (Sigma, St. Louis, MO, USA), and the concentration was calculated using the area for each peak.

\section{Amino acids}

Meat samples (5 g) were mixed with $40 \mathrm{~mL}$ of $6 \mathrm{~N} \mathrm{HCl}$ and hydrolyzed for $24 \mathrm{~h}$ at $110^{\circ} \mathrm{C}$. The hydrolyzed meat samples were concentrated with a rotary evaporator (Eyela, Tokyo, Japan) to remove $\mathrm{HCl}$, and the residue was cleaned 3 times with distilled water and filtered with filter paper (Toyo, No. 5B). The filtrate was made up to a volume of $50 \mathrm{~mL}$ with distilled water and then analyzed with an amino acid analyzer (Hitachi L-8500A, Tokyo, Japan). Prior to adding $\mathrm{HCl}$, cysteine and methionine were converted to cysteic acid and methione sulfone using $20 \mathrm{~mL}$ of a stabilizing solution (85\% formic acid 45 $\mathrm{mL}+30 \% \mathrm{H}_{2} \mathrm{O}_{2} 5 \mathrm{~mL}$.

\section{Texture analysis}

The meat samples were homogenized through 6-mm plates and chicken breast and thigh meat patties $(5 \mathrm{~cm}$ diameter, $2 \mathrm{~cm}$ thickness and $30 \mathrm{~g}$ weight) were prepared. Half of each breast and thigh patty was cooked to an internal temperature of $75^{\circ} \mathrm{C}$ to prepare the cooked meat samples. The centers of the raw and cooked meat samples were compressed twice to $75 \%$ of their original height using a texture analyzer (Model A-XT2, Stable micro systems, Surrey, UK) attached with a needle $(15 \mathrm{~mm}$ diameter) at a test speed of $5.00 \mathrm{~mm} / \mathrm{sec}$ and a trigger force of $0.005 \mathrm{~kg}$.

\section{Sensory evaluation}

For the sensory evaluation, the meat samples were heated in a pan to an internal temperature of $75^{\circ} \mathrm{C}$, using a gas burner. The meat samples $(2 \times 3 \times 1.5 \mathrm{~cm})$ were placed into coded white dishes and served with drinking water. Ten semi-trained panelists recorded their preferences via 9-point hedonic scales $(1=$ profoundly dislike, $5=$ moderately like, $9=$ profoundly like). The sensory parameters tested were color, odor, taste, texture, and overall acceptance. All samples were labeled with random 3-digit numbers and presented to the panelists in random order. For sensory evaluation, the panelists were asked to subjectively grade the color, odor, taste, texture, and overall acceptability of the samples.

\section{Statistical analysis}

Analysis of variance was conducted via the procedure of the General Linear Model using SAS version 9.1 software (2002-2003 by SAS Institute Inc.). Duncan's multiple range tests were utilized to compare the significant differences of the mean values of treatments $(p<0.05)$. The mean values and standard errors of the means (SEM) were reported. 


\section{Results and Discussion}

\section{Proximate composition}

The proximate composition of the KNC (average weight $1,369 \mathrm{~g}$ ) and CB (average weight 1,183 g) is indicated in Table 1. The crude fat contents of the thighs of KNC $(2.98 \%)$ were significantly lower than those recorded in the $\mathrm{CB}(4.74 \%)$ and the crude ash contents measured in the KNC $(0.96 \%)$ were higher than those of CB $(0.47 \%)$. This result is consistent with the report of Young and Choi (2003), in that the fat contents of traditional Korean chickens were lower than those of the general broilers.

The crude protein and ash contents were higher in the breast meat than in the thigh, and the crude fat contents were higher in the thigh meat than the breast meat, regardless of the chicken species. This result is also consistent with the report of Xiong et al. (1993). Therefore, the relatively low fat and high ash content of the KNC thigh meat may be considered a unique compositional characteristic. The low fat contents of the KNC thigh meat indicate a lower caloric content than the CB.

\section{pH, WHC and color}

Table 2 shows the $\mathrm{pH}$, WHC, and color values of KNC and $\mathrm{CB}$. The $\mathrm{pH}$ of the $\mathrm{KNC}$ breast muscles (5.87) was lower than that of the $\mathrm{CB}$ breast muscles (6.21), but we noted no differences between the thigh meat of the KNC and CB. No different results were noted between the two chicken species in terms of WHC.

With regard to color values, the $\mathrm{L}^{*}$ values of the $\mathrm{KNC}$ breast were higher than those of the $\mathrm{CB}$, but the $\mathrm{a}^{*}$ and $\mathrm{b}^{*}$ values of the $\mathrm{KNC}$ breast were lower than those measured in the $\mathrm{CB}$. The higher $\mathrm{L}^{*}$ values of the $\mathrm{KNC}$ breast might be related to these lower $\mathrm{pH}$ values. Barbut (1993) previously reported that $\mathrm{pH}$ was correlated negatively

Table 1. General composition (\%) of the breast and thigh meat from commercial Korean native chickens (KNC) and broilers (CB)

\begin{tabular}{llccll}
\hline \hline & & Moisture & $\begin{array}{c}\text { Crude } \\
\text { protein }\end{array}$ & Crude fat & Crude ash \\
\hline \multirow{3}{*}{ Breast } & KNC & 72.07 & 23.75 & 2.53 & 1.14 \\
& CB & 72.09 & 23.97 & 2.27 & 1.03 \\
& SEM $^{1)}$ & 0.755 & 0.204 & 0.170 & 0.092 \\
\hline \multirow{4}{*}{ Thigh } & KNC & 75.62 & 19.84 & $2.98^{\mathrm{b}}$ & $0.96^{\mathrm{a}}$ \\
& $\mathrm{CB}^{\mathrm{a}}$ & 75.15 & 19.45 & $4.74^{\mathrm{a}}$ & $0.47^{\mathrm{b}}$ \\
& $\mathrm{SEM}^{1)}$ & 0.623 & 0.135 & 0.298 & 0.104 \\
\hline
\end{tabular}

$\overline{\mathrm{a}, \mathrm{b}}$ Means within the same column with different superscript differ significantly $(p<0.05)$.

${ }^{1)}$ Standard errors of the mean $(n=10)$.
Table 2. pH, water holding capacity (WHC) and color values of the breast and thigh meat from commercial Korean native chickens (KNC) and broilers (CB)

\begin{tabular}{llccccc}
\hline \hline & & $\mathrm{pH}$ & WHC & CIE L* $^{*}$ & CIE a* $^{*}$ & CIE b* $^{*}$ \\
\hline \multirow{5}{*}{ Breast } & KNC & $5.87^{\mathrm{b}}$ & 47.75 & $56.61^{\mathrm{a}}$ & $2.21^{\mathrm{b}}$ & $14.30^{\mathrm{b}}$ \\
& $\mathrm{CB}$ & $6.21^{\mathrm{a}}$ & 48.28 & $48.67^{\mathrm{b}}$ & $7.78^{\mathrm{a}}$ & $21.72^{\mathrm{a}}$ \\
& SEM $^{1)}$ & 0.006 & 2.053 & 0.168 & 0.192 & 0.257 \\
\hline \multirow{4}{*}{ Thigh } & $\mathrm{KNC}^{2}$ & 6.55 & 36.64 & 48.19 & 8.28 & $12.62^{\mathrm{b}}$ \\
& $\mathrm{CB}$ & 6.56 & 32.92 & 48.92 & 9.06 & $18.87^{\mathrm{a}}$ \\
& SEM $^{1)}$ & 0.013 & 2.413 & 0.760 & 0.435 & 0.770 \\
\hline
\end{tabular}

$\overline{\mathrm{a}, \mathrm{b}}$ Means within the same column with different superscript differ significantly $(p<0.05)$.

${ }^{1)}$ Standard errors of the mean $(n=10)$.

with lightness in turkey breast muscles. Thus, the brighter color of KNC breast can be attributed to relatively lower $\mathrm{pH}$ values. The CIE $\mathrm{b}^{*}$ values of the $\mathrm{KNC}$ thigh meat were lower than those of the CB thighs.

Therefore, in terms of overall color, the $\mathrm{KNC}$ were brighter than the $\mathrm{CB}$. This difference in color might represent an important factor affecting consumers' preferences, considering that Bianchi et al. (2007) reported that consumers preferred different colors, depending on their place of residence.

\section{Fatty acid composition}

Table 3 provides the major fatty acids of the $\mathrm{KNC}$ and CB breast and thigh muscles. Based on the report of Sung et al. (1998), palmitic acid (C16:0), oleic acid (C18:1), and linoleic acid (C18:2) are the principal fatty acids in traditional Korean native chickens. In the breast muscles, palmitic (30.76\%) and arachidonic acid (4.26\%) contents were higher in the KNC than in the CB. However, no significant differences in other fatty acids were noted. In the thigh meat, palmitic acid (26.36\%) contents were higher in the $\mathrm{KNC}$ than in the $\mathrm{CB}$.

Essential fatty acids including n- 6 fatty acids such as

Table 3. Fatty acid composition (\%) of the breast and thigh meat from commercial Korean native chicken (KNC) and broiler (CB)

\begin{tabular}{llrcccl}
\hline \hline & & C16:0 & C18:0 & C18:1 & C18:2 & C20:4 \\
\hline \multirow{4}{*}{ Breast } & KNC & $30.76^{\mathrm{a}}$ & 16.38 & 32.16 & 16.42 & $4.26^{\mathrm{a}}$ \\
& CB & $28.10^{\mathrm{b}}$ & 18.92 & 36.74 & 13.29 & $2.93^{\mathrm{b}}$ \\
& SEM $^{1)}$ & 0.050 & 1.360 & 0.982 & 0.590 & 0.180 \\
\hline \multirow{4}{*}{ Thigh } & KNC & $26.36^{\mathrm{a}}$ & 20.03 & 28.57 & 18.71 & 6.30 \\
& SEM $^{1)}$ & $23.06^{\mathrm{b}}$ & 20.80 & 30.98 & 19.41 & 5.74 \\
& 0.428 & 0.804 & 1.277 & 0.266 & 0.331 \\
\hline
\end{tabular}

${ }^{\mathrm{a}, \mathrm{b}}$ Means within the same column with different superscript differ significantly $(p<0.05)$.

${ }^{1)}$ Standard errors of the mean $(n=10)$. 
linoleic acid and arachidonic acid are critically important in humans, because they cannot be biogenerated in the living body and must be supplied in dietary form (Cho et al., 2008). Consequently, the high arachidonic acid content in $\mathrm{KNC}$ is an attractive nutritional quality factor.

Oleic acid is a major fatty acid related to meat flavor (Dayden and Maechello, 1970). Although we noted no significant differences in oleic acid content between KNC and $\mathrm{CB}$, oleic acid was the predominant fatty acid, detected in a range of $28-36 \%$. This result is consistent with the report that poultry meat contained higher unsaturated fatty acid contents than were measured in red meats (Mountney, 1976).

\section{Nucleotides content}

The contents of nucleotides associated with meat flavor were analyzed in both $\mathrm{KNC}$ and $\mathrm{CB}$ (Table 4). The inosine contents of the KNC thigh meat (193.87 $\mu \mathrm{g} / \mathrm{g}$ ) were lower than those measured in the CB thigh meat (263.81 $\mu \mathrm{g} / \mathrm{g}$ ), but the other nucleic acid compounds did not differ greatly. The concentrations of IMP in muscles from Korean native chickens were, by 15 wk of age, higher than those in broiler chickens (Ahn and Park, 2002). Although IMP has been identified as the predominant nucleic acid responsible for meaty flavor (Kawamura and Halpern, 1987), no significant difference between KNC and $\mathrm{CB}$ was identified in this study. The amounts of free amino acids and peptides increased during the aging period, but IMP content decreased as it was converted to hypoxanthine through inosine (Yano et al., 1995). Thus, this lack of difference in IMP content between KNC and $\mathrm{CB}$ can be attributed to the prolonged storage of the meat samples used in this study. Further experiments using

Table 4. Nucleotide contents $(\mu \mathrm{g} / \mathrm{g}$ meat) of the breast and thigh meat from commercial Korean native chickens (KNC) and broilers (CB)

\begin{tabular}{llrrrr}
\hline \hline & & AMP & IMP & Inosine & $\begin{array}{c}\text { Hypoxan- } \\
\text { thine }\end{array}$ \\
\hline Breast & KNC & 91.098 & 2242.788 & 458.726 & 698.543 \\
& SEM $^{2)}$ & 101.275 & 2132.654 & 555.085 & 592.151 \\
Thigh & 11.142 & 247.197 & 49.858 & 85.175 \\
\hline & KNC $^{23}$ & tr $^{3)}$ & 898.255 & $193.865^{\mathrm{b}}$ & 1354.435 \\
& SEM $^{2)}$ & - & 892.482 & $263.811^{\mathrm{a}}$ & 1091.206 \\
\hline
\end{tabular}

${ }_{\mathrm{a}, \mathrm{b}}$ Means within the same column with different superscript differ significantly $(p<0.05)$.

${ }^{1)}$ Abbreviation : AMP, Adenosine-5'-phosphate; IMP, Inosine-5'phosphate.

${ }^{2)}$ Standard errors of the mean $(n=10)$.

${ }^{3)}$ Trace amount was detected but could not be quantified. fresher meat samples will be necessary in order to measure nucleotide contents more precisely.

\section{Amino acid composition}

Amino acids, as well as nucleic acids, are relevant to meaty flavor. In breast meat, KNC evidenced higher glycine, alanine, and proline contents, which are known to be associated with the superior flavor of $\mathrm{KNC}$ relative to $\mathrm{CB}$ (Fukunaga et al., 1989). On the other hand, phenylalanine contents were higher in CB than in KNC. Phenylalanine has been shown to be closely associated with a bitter taste in meat (Fukunaga et al., 1989). However, we detected no significant differences in amino acid composition between the thigh meat samples. Batzer et al. (1960) previously reported that although many amino acids were involved with the taste and odor of meat, tyrosine and phenylalanine were not particularly relevant to meat flavor. They also reported that when many amino acids were mixed with sugar compounds, a rich meat flavor was produced. Among amino acids, glutamic acid was one of the most influential compounds on chicken meat flavor, singly or in combination with other taste-associated compounds (Kurihara, 1987).

\section{Texture and sensory characteristics}

Table 6 shows the texture properties of KNC and CB. In raw chicken breast samples, KNC was graded as hav-

Table 5. Amino acid composition (\%) of the breast and thigh meat from commercial Korean native chickens (KNC) and broilers (CB)

\begin{tabular}{llllllll}
\hline \hline & \multicolumn{3}{c}{ Breast } & & & \multicolumn{2}{c}{ Thigh } \\
\cline { 2 - 5 } \cline { 7 - 8 } & KNC & CB & SEM $^{1)}$ & & KNC & CB & SEM $^{1)}$ \\
\hline Cysteine & 0.25 & 0.26 & 0.003 & & 0.21 & 0.23 & 0.004 \\
Methionine & 0.58 & 0.58 & 0.014 & & 0.48 & 0.50 & 0.011 \\
Asparagine & 2.29 & 2.13 & 0.052 & & 1.86 & 1.74 & 0.062 \\
Threonine & 1.11 & 1.03 & 0.026 & & 0.91 & 0.85 & 0.030 \\
Serine & 0.96 & 0.91 & 0.023 & & 0.82 & 0.78 & 0.030 \\
Glutamic acid & 3.67 & 3.38 & 0.097 & & 3.09 & 2.96 & 0.119 \\
Glycine & $1.03^{\mathrm{a}}$ & $0.94^{\mathrm{b}}$ & 0.018 & & 0.83 & 0.76 & 0.025 \\
Alanine & $1.40^{\mathrm{a}}$ & $1.29^{\mathrm{b}}$ & 0.028 & & 1.11 & 1.04 & 0.033 \\
Valine & 0.95 & 0.88 & 0.020 & & 0.75 & 0.70 & 0.022 \\
Isoleucine & 0.90 & 0.83 & 0.020 & & 0.72 & 0.67 & 0.021 \\
Leucine & 2.00 & 1.83 & 0.054 & & 1.59 & 1.50 & 0.057 \\
Tyrosine & 0.71 & 0.65 & 0.022 & & 0.57 & 0.55 & 0.023 \\
Phenylalanine & $0.59^{\mathrm{b}}$ & $0.82^{\mathrm{a}}$ & 0.016 & & 0.74 & 0.71 & 0.034 \\
Lysine & 2.06 & 1.91 & 0.052 & & 1.67 & 1.59 & 0.062 \\
Histidine & 0.72 & 0.79 & 0.026 & & 0.52 & 0.51 & 0.018 \\
Arginine & 1.48 & 1.36 & 0.036 & & 1.18 & 1.12 & 0.040 \\
Proline & $0.91^{\mathrm{a}}$ & $0.81^{\mathrm{b}}$ & 0.020 & & 0.75 & 0.71 & 0.028 \\
\hline
\end{tabular}

\footnotetext{
${ }^{a, b}$ Means within the same row with different superscript differ significantly $(p<0.05)$.

${ }^{1)}$ Standard errors of the mean $(n=10)$.
} 
Table 6. Comparison of texture characteristics of the breast and thigh meat from commercial Korean native chickens (KNC) and broilers (CB)

\begin{tabular}{|c|c|c|c|c|c|c|c|}
\hline & & & Hardness & Springiness & Cohesiveness & Gumminess & Chewiness \\
\hline \multirow{6}{*}{ Raw } & \multirow{3}{*}{ Breast } & $\mathrm{KNC}$ & 0.36 & 0.90 & $0.48^{\mathrm{a}}$ & $0.17^{\mathrm{a}}$ & $0.16^{\mathrm{a}}$ \\
\hline & & $\mathrm{CB}$ & 0.34 & 0.91 & $0.42^{\mathrm{b}}$ & $0.14^{\mathrm{b}}$ & $0.13^{\mathrm{b}}$ \\
\hline & & $\mathrm{SEM}^{1)}$ & 0.015 & 0.027 & 0.017 & 0.006 & 0.008 \\
\hline & \multirow{3}{*}{ Thigh } & KNC & $0.52^{\mathrm{a}}$ & 0.94 & 0.40 & $0.21^{\mathrm{a}}$ & $0.20^{\mathrm{a}}$ \\
\hline & & $\mathrm{CB}$ & $0.31^{\mathrm{b}}$ & 0.88 & 0.43 & $0.13^{\mathrm{b}}$ & $0.12^{\mathrm{b}}$ \\
\hline & & $\mathrm{SEM}^{1)}$ & 0.010 & 0.021 & 0.010 & 0.004 & 0.003 \\
\hline \multirow{6}{*}{ Cooked } & \multirow{3}{*}{ Breast } & $\mathrm{KNC}$ & 6.84 & 0.82 & 0.35 & 2.46 & 2.04 \\
\hline & & $\mathrm{CB}$ & 7.42 & 0.78 & 0.35 & 2.68 & 2.12 \\
\hline & & $\mathrm{SEM}^{1)}$ & 0.657 & 0.015 & 0.020 & 0.315 & 0.274 \\
\hline & \multirow{3}{*}{ Thigh } & $\mathrm{KNC}$ & $5.11^{\mathrm{a}}$ & 0.83 & $0.44^{\mathrm{a}}$ & $2.36^{\mathrm{a}}$ & $1.94^{\mathrm{a}}$ \\
\hline & & $\mathrm{CB}$ & $4.32^{\mathrm{b}}$ & 0.82 & $0.37^{\mathrm{b}}$ & $1.60^{\mathrm{b}}$ & $1.32^{\mathrm{b}}$ \\
\hline & & SEM $^{1)}$ & 0.138 & 0.008 & 0.020 & 0.138 & 0.106 \\
\hline
\end{tabular}

a,b Means within the same column with different superscript differ significantly $(p<0.05)$.

${ }^{1)}$ Standard errors of the mean $(\mathrm{n}=10)$.

ing higher cohesiveness, gumminess, and chewiness values than $\mathrm{CB}$, respectively. In raw thigh meat, $\mathrm{KNC}$ evidenced hardness values higher than those of $\mathrm{CB}$.

In the cooked chicken thigh meat samples, $\mathrm{KNC}$ was graded as having higher hardness, cohesiveness, gumminess, and chewiness values. Therefore, KNC was regarded as a more cohesive and gummy chicken meat than CB. Another study using KNC cultivated by the Korea Rural Development Administration showed that the collagen contents of this particular KNC variety were 1.6 and 1.55 times higher in the breast and leg meat than those of CB, respectively (data not shown). These results also reflect the unique textural properties of KNC.

Sensory characteristics (color, odor, taste, texture, and overall acceptance), however, did not differ substantially between KNC and CB, as is shown in Table 7. Further study will be required to elucidate these differences, by preparing samples with the same environmental factors, including feed, age, and/or live weight between two chicken species.

$\mathrm{KNC}$ breast had lower fat content than CB. Even though

Table 7. Comparison of sensory characteristics of the boiled breast and thigh meat from commercial Korean native chickens (KNC) and broilers (CB)

\begin{tabular}{|c|c|c|c|c|c|c|}
\hline & & Color & Odor & Taste & Texture & $\begin{array}{c}\text { Overall } \\
\text { acceptance }\end{array}$ \\
\hline \multirow{3}{*}{ Breast } & $\mathrm{KNC}$ & 5.45 & 5.54 & 6.00 & 5.72 & 5.81 \\
\hline & $\mathrm{CB}$ & 5.81 & 5.36 & 5.63 & 5.27 & 5.36 \\
\hline & SEM $^{1)}$ & 0.318 & 0.433 & 0.360 & 0.532 & 0.416 \\
\hline \multirow{3}{*}{ Thigh } & $\mathrm{KNC}$ & 5.27 & 5.18 & 6.27 & 6.27 & 6.09 \\
\hline & $\mathrm{CB}$ & 5.63 & 5.81 & 5.63 & 5.36 & 5.63 \\
\hline & SEM $^{1)}$ & 0.440 & 0.295 & 0.291 & 0.348 & 0.326 \\
\hline
\end{tabular}

${ }^{1)}$ Standard errors of the mean $(\mathrm{n}=10)$. the $\mathrm{pH}$ values of $\mathrm{KNC}$ breast meat were lower than those of the $\mathrm{CB}$ breast, we noted no significant differences in water holding capacity. The $\mathrm{L}^{*}$-value of $\mathrm{KNC}$ breast was higher than $\mathrm{CB}$, and this may be related to the lower $\mathrm{pH}$ values of the $\mathrm{KNC}$ breast. The $\mathrm{a}^{*}$ - and $\mathrm{b}^{*}$-values tended to be higher in $\mathrm{CB}$ than $\mathrm{KNC}$. The KNC breasts harbored higher palmitic acid and arachidonic acid contents than $\mathrm{CB}$, and the KNC thighs harbored higher palmitic acid contents. The $\mathrm{CB}$ thighs contained higher inosine contents, but KNC contained higher concentrations of glycine, alanine, and proline. Raw and cooked KNC breast samples evidenced higher cohesiveness, gumminess, and chewiness values than those of $\mathrm{CB}$, and the raw $\mathrm{KNC}$ thigh samples had higher hardness values. According to our results, there are some distinctively different physicochemical properties between KNC and CB. For a more precise comparison between the two chicken species, environmental factors should be controlled prior to assessment.

\section{Acknowledgement}

This work was supported by the Korea Rural Development Administration Fund.

\section{References}

1. Ahn, D. H. and Park, S. Y. (2002) Studies on components related to taste such as free amino acids and nucleotides in Korean native chicken meat. J. Korean soc. Food Sci. Nutr. 31, 547-552.

2. Ahn, D. H., Park, S. Y., Kwon, Y. J., and Sung, S. K. (1997) 
Postmortem changes in myofibrillar protein in muscle of Korean native chicken. Korean J. Anim. Sci. 39, 577-586.

3. AOAC (1990) Official methods of analysis. 15th ed, Association Official Analytical Chemists, Washington, DC. pp. 931.

4. Barbut, S. (1993) Colour measurements for evaluating the pale soft exudative (PSE) occurrence in turkey meat. Food Res. Int. 26, 39-43.

5. Batzer, O. F., Santoro, A. T., Tan, M. C., Landmann, W. A., and Schweigert, B. S. (1960) Precursors of beef flavor. $J$. Agric. Food Chem. 8, 498-501.

6. Bianchi, M., Petracci, M., Sirri, F., Folegatti, E., Franchini, A., and Meluzzi A. (2007) The Influence of the season and market class of broiler chickens on breast meat quality traits. Poultry Sci. 86, 959-963.

7. Chae, H. S., Cho, S. H., Park, B. Y., Yoo, Y. M., Kim, J. H., Ahn C. N., Lee, J. M., Kim, Y. K., and Choi, Y. I. (2002) Changes of the fatty acid, amino acids and collagen contents in domestic broiler chickens of different marketing standard. Korean J. Food Sci. Ani. Resour. 22, 1-7.

8. Cho, S. H., Seong, P. N., Kim, J. H., Park, B. Y., Baek, B. H., Lee, Y. J., In, T. S., Lee, J. M., Kim, D. H., and Ahn, J. N. (2008) Calorie, cholesterol, collagen, free amino acids, nucleotide-related compounds and fatty acid composition of Hanwoo steer beef with $1^{++}$quality grade. Korean J. Food Sci. Ani. Resour. 28, 333-343.

9. Ding, H., Xu, H. J., and Chan, D. K. O. (1999) Identification of broiler chicken meat using a visible/near-infrared spectroscopic technique. J. Sci. Food Agric. 79, 1382-1388.

10. Dryden, F. D. and Maechello, J. A. (1970) Influence of total lipid and fatty acid composition upon the palatability of three bovine muscles. J. Anim. Sci. 31, 36-41.

11. Folch, J. M., Lee, M., and Sloan Stanley G. H. (1957) A simple method for the isolation and purification of total lipids from animal tissues. J. Biol. Chem. 226, 497-509.

12. Fukunaga, T., Koga, K., Maita, Y., and Matsuoka, S. (1989) Free amino acid, carnosine and 5'-inosinic acid contents in the breast and leg meats from the cross and tripe-cross chickens of Satsuma native fowl. Bull. Fac. Agric. Kagoshima Univ. 39, 223-232.

13. Kawamura, Y. and Halpern, B. P. (1987) Recent developments in umami research. In: Umami: a basic taste. Kawa- mura, Y. Kare MR (eds), Marcell Dekker, NY, pp. 637-642.

14. Kim, Y. H., Min, J. S., Hwang, S. G., Lee, S. O., Kim, I. S., Park, H. I., and Lee, M. H. (1999) Fatty acids composition and sensory characteristics of the commercial native chicken meat. Korean J. Food Sci. Technol. 31, 964-970.

15. Kurihara K. (1987) Recent progress in the taste receptor. In Umami: a basic taste. Kawamura, Y. Kare MR (eds), Marcel Dekker, NY. pp 3-39.

16. Montney, G. J. (1976) Poultry products technology. AVI Pub. Co., Westport, CT, USA.

17. Rural Development Administration. (2008). Online available: http://www.rda.go.kr.

18. Ryoichi, S., Degychi, T., and Nagata, Y. (1993) Effectiveness of the filter paper press methods for determining the water holding capacity of meat. Fleischwirtsch 73, 1399.

19. Saegusa, H., Hirano H., Ozawa S., Goda, Y., Shimada, N., and Saito, S. (1987) Differences in concentration of free amino acid in breast and thigh muscles from Japanese game chicken and broiler. Jpn. J. Zootech. Sci. 58, 707-710.

20. Sung, S. K., Kwon, Y. J., and Kim, D. G. (1998) Postmortem changes in the physico-chemical characteristics of Korean native chicken. Korean J. Poult. Sci. 25, 55-64.

21. Wattanachant, S., Benjakul, S., and Ledward, D. A. (2004) Composition, color, and texture of Thai indigenous and broiler chicken muscles. Poultry Sci. 83, 123-128.

22. Xiong, Y. L., Cantor, A. H., Pescatore, A. J., Blanchard, S. P., and Straw, M. L. (1993) Variations in muscle chemical composition, $\mathrm{pH}$ and protein extractability among eight different broiler crosses. Poultry Sci. 72, 583-588.

23. Yamaguchi, S. (1991) Roles and efficacy of sensory evaluation in studies of taste. J. Japan Soc. Food Sci. Technol. 38, 972-978.

24. Yano, T., Kataho, N., Watanabe, M., Nakamura, T., and Asano, Y. (1995) Evaluation of beef aging by determination of hypoxanthine and xanthine contents: application of a xanthine sensor. Food Chem. 52, 439-445.

25. Young, H. T. and Choi, H. J. (2003) Studies on nutrient components between the Chungjung chicken meats and general chicken meats. Korean J. Food Nutr. 16, 187-191.

(Received 2009.6.7/Revised 1st 2009.9.6, 2nd 2009.12.22/Accepted 2009.12.28) 